\title{
Inhaled Corticosteroid Therapy-The Impact of Formulary Changes on Asthma Control
}

\author{
An Expert Interview with Scott Bickel
}

Division of Pediatric Pulmonology, University of Louisville, Louisville, KY, USA

DOI: https://doi.org/10.17925/USPRD.2019.4.1.10

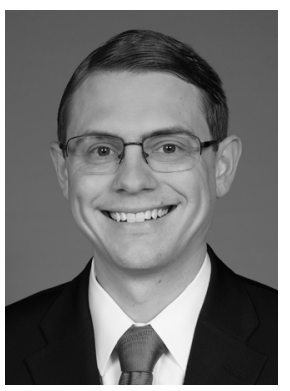

\section{Scott Bickel}

After graduating with a Bachelor of Science in Computer Science from Ohio State University, Scott received his medical degree from the University of Louisville. He stayed in Louisville to complete his pediatric residency and then became the first pediatric pulmonology fellow at the University of Louisville. Upon completion of his fellowship, Scott joined the faculty at the University of Louisville as part of the Division of Pediatric Pulmonology. He has special interests in pulmonary function testing, optimizing asthma care, and fellow, resident and student medical education. As such, he serves as the Assistant Program Director for the Pediatric Pulmonology Fellowship. Scott has published in peer-reviewed journals on the clinical applications of impulse oscillometry, pediatric medical education, and barriers to adherence in asthma.

\section{Keywords}

Inhaled corticosteroid therapy,

asthma, lung function

Disclosure: Scott Bickel has nothing to declare in relation to this article.

Review Process: This is an expert interview and as such has not undergone the journal's standard peer review process.

Compliance with Ethics: This article is an expert interview and does not report on new clinical data, or any studies with human or animal subjects performed by any of the authors.

Authorship: The named author meets the International Committee of Medical Journal Editors (ICMJE) criteria for authorship of this manuscript, takes responsibility for the integrity of the work as a whole, and has given final approval for the version to be published.

Received: December 9, 2019

Published Online: January 27, 2020

Citation: US Respiratory \& Pulmonary Diseases. 2019;4(1):10-1

Corresponding Author: Scott Bickel, University of Louisville Division of Pediatric Pulmonology, Suite 414, 571 South Floyd Street, Louisville, KY 40202, USA. E: scott.bickel@|ouisville.edu

Support: No funding was received for the publication of this article. nhaled corticosteroid (ICS) therapy is a cornerstone of asthma management. In the USA, selection of specific ICS for patients is frequently directed by insurance formulary coverage, which can change abruptly and often without timely notification. There are scant data on the impact of these changes in pediatric asthma patients. In 2016, a major regional Medicaid provider in Kentucky discontinued coverage of beclomethasone dipropionate (BDP), available only in traditional metered dose inhaler (MDI) form at that time, in favor of mometasone furoate, available in both MDI and dry powder inhaler (DPI) form. Anecdotally, this change caused considerable confusion among both providers and families. We sought to characterize the objective impact of this change by examining prescription patterns and the patient's lung function pre- and post-change. We recently presented our data at the 2019 CHEST Conference.

\section{Q. Why did Medicaid discontinue coverage of beclomethasone dipropionate in favor of mometasone furoate?}

A definitive reason for the change has not been divulged. Most formulary changes of this nature are done for economic reasons, the plan being able to acquire one drug at a lesser cost than another. These changes are quite common with asthma maintenance medications and very disruptive to long-term management due to the confusion they create for patients, families, and healthcare professionals.

\section{Q. What was the rationale for investigating the impact of this change on the pediatric population?}

Insurance formulary changes have been a major reason why many of our children with asthma, who were otherwise stable, have been switched from one long-term controller to another. Children with asthma are a unique population in that they are often not able to use certain breath-actuated inhalers correctly which can lead to loss of control. Anecdotally, these changes cause considerable confusion and frustration for both families and healthcare professionals. In doing this study, we sought to provide objective data on how these changes influence prescribing patterns and lung function. ${ }^{1}$

\section{Q. Could you tell us a little about your study and its effect on lung function?}

We performed a retrospective chart review on children with asthma, aged 6-18 from a large, university-based general pediatric clinic, with a predominately Medicaid population who were seen and had spirometry done both before (February to July 2016) and after (February to July 2017) the 
relevant formulary change from BDP to mometasone furoate. ${ }^{1}$ Importantly, mometasone furoate was available in both DPI and MDI forms while BDP was available only in a traditional MDI at the time. Prior to the formulary change, 67 out of 68 (98.5\%) patients on inhaled controller therapy were on an MDI, compared to 39 out of 65 (60\%) after the change. Of those initially on BDP, 24 out of 59 (41\%) had been switched to a DPI. Of these 24 patients switched to a DPI, the average forced expiratory volume in 1 second $\left(\mathrm{FEV}_{1}\right.$ ) was $99 \%$ predicted prior to the change and $89 \%$ predicted after being transitioned $(p=0.01)$. A statistically significant decline was also seen in forced expiratory flow at $25-75 \%\left(\mathrm{FEF}_{25-75 \%}\right)$ where the average was $89 \%$ predicted prior to the change and $77 \%$ afterwards $(p=0.04)$. Of those who remained on an MDI, there was no statistically significant change in lung function ( $\mathrm{FEV}_{1} 101 \%$ pre-change, $98.9 \%$ post-change, $\left.\mathrm{p}=0.68\right){ }^{1}{ }^{1}$

\section{Q. What factors could explain these findings?}

As a result of the formulary changes, many children with asthma were prescribed DPIs which required a very different technique for using them compared with their previous MDIs. We suspect this change in inhaler type lead to confusion and a decline in adherence (whether intentional or unintentional). Some children, even if attempting to use these devices correctly, may have been unable to generate the inspiratory force needed to actuate the inhaler and deliver the medication.

\section{Q. In future, how can we minimize the impact of formulary changes in this vulnerable patient group?}

Insurance providers should be partners with healthcare professionals in ensuring that all children with asthma have easy access to inhalers that they are capable of using and best suited for the child's individualized care. The short-term financial advantages of formulary switching should not outweigh the potential harm to children, increased administrative burden to health care professionals and possible increased long-term costs associated with loss of asthma control. $\square$

1. Bickel S, Canal C, Eid N, Sayat J. Do inhaled corticosteroid formulary changes impact control in pediatric asthma? CHEST. 2019;156:A850 